\section{Expanding portion sizes in the US marketplace: Implications for nutrition counseling}

\author{
LISA R. YOUNG, PhD, RD; MARION NESTLE, PhD, MPH
}

\section{ABSTRACT}

The greater energy content of larger food portions could be contributing to the increasing prevalence of overweight. Prevention guidelines recommend "sensible" portion sizes but do not define them. The US Department of Agriculture (USDA) defines standard serving sizes for dietary guidance, and the Food and Drug Administration (FDA) defines standard servings for food labels. To use these standards in counseling, nutritionists must know the sizes of portions available in the marketplace. We determined marketplace portion sizes, identified changes in these sizes with time, and compared current marketplace portions with federal standards. Most marketplace portions exceed standard serving sizes by at least a factor of 2 and sometimes 8-fold. Portions have increased over time; those offered by fast-food chains, for example, often are 2 to 5 times larger than the original size. The discrepancy between marketplace portions and standard servings suggests the need for greater emphasis on the relationship of portion size to energy intake as a factor in weight maintenance. J Am Diet Assoc. 2003;103:231-234.

$\mathbf{T}$ he portion sizes of commonly consumed foods appear to have increased in size during the past 20 years (1). Larger food portions provide more energy (kcal) than smaller portions and could be contributing to the increased prevalence of overweight and obesity since the 1970s (2-4). The 2001 Surgeon General's Call to Action on obesity prevention stressed the need to address portion size as a factor in weight control, raise consumer awareness of reasonable portion sizes, and encourage food companies to provide reasonably sized portions (5). Because larger portions have become typical, consumers have increasing difficulty recognizing amounts of food that are appropriate for their weight and activity levels $(6,7)$. Although the Call to Action advised consumers to "choose sensible portions," it did not define the sizes of such portions (8).

Nutritionists use two sets of standard serving sizes when counseling clients about healthful eating and weightloss strategies: one developed by the US Department of Agriculture (USDA) for dietary guidance and the other by the Food and Drug Administration (FDA) for food labeling. Both define serving sizes of specific weight and volume and, therefore, energy and nutrient content. The USDA's Food Guide Pyramid, for example, lists the sizes of standard grain servings as follows: 1 slice bread, $1 / 2$ cup cooked pasta, $1 / 2$ bagel, or 1 oz ready-to-eat cereal (9). In

L. R. Young is adjunct assistant professor, and M. Nestle is professor and chair of the Department of Nutrition and Food Studies, New York University (NYU), NY.

Address correspondence to: Lisa R. Young, PhD, RD, Department of Nutrition and Food Studies, New York University, 35 W. 4th St., 10th Floor, New

York, NY10012-1172.E-mail: lisa.young@nyu.edu

Copyright (C) 2003 by the American Dietetic Association.

0002-8223/03/10302-0018\$35.00/0

doi: 10.1053/jada.2003.50027

defining standard servings, the USDA considered nutrient content, ease of use, tradition, and typical intake based on median amounts reported in the 1977-1978 Nationwide Food Consumption Survey (NFCS) (10-12). When the 2000 edition of the Dietary Guidelines advises choosing "sensible portions," it refers to Pyramid serving definitions (13). The FDA defines somewhat different serving sizes for Nutrition Facts labels. These were intended to represent amounts of foods commonly consumed based on data from dietary intake surveys: the National Food Consumption Surveys of 1977-1978 and 1987-1988 and the 1985-1986 Continuing Survey of Food Intake of Individuals (CSFII) $(14,15)$. Because the surveys were conducted 15 to 25 years ago, standard servings may be smaller than marketplace portions (16). If so, nutritionists need to be able to compare serving size standards with the sizes of foods purchased ("marketplace portions") and, presumably, consumed; nearly half of all food expenditures are for items prepared and served outside the home (17). However, because so little is known about the sizes of marketplace portions, we measured them directly and compared them with USDA and FDA standards. We also investigated trends in portion sizes to determine whether they correlate to rising rates of obesity.

\section{METHODS}

We examined the sizes of ready-to-eat foods from take-out places, fast-food outlets, and family-type restaurants; these account for much of the recent increase in out-of-home food consumption, rank highest in sales, and exhibit the highest sales growth (18-20). We sampled foods from categories reported in national surveys as major contributors of energy in US diets and marketed as single portions: white bread products, cakes, alcoholic beverages, hamburgers, steak, soda, french fries, pasta, and pizza $(21,22)$. We obtained size information from package labels or from manufacturers. When such information was unavailable, and to confirm the accuracy of label weights and manufacturers' information, we weighed at least two samples of each food item from the same location using a calibrated Sysco Digital Portion Scale (Model SDS-10; Sysco Foodservice, Houston, TX) and recorded average weights. A pilot project 
Table 1

Measured sizes of ready-to-eat prepared foods (marketplace portions) compared with USDA' and FDA serving sizes

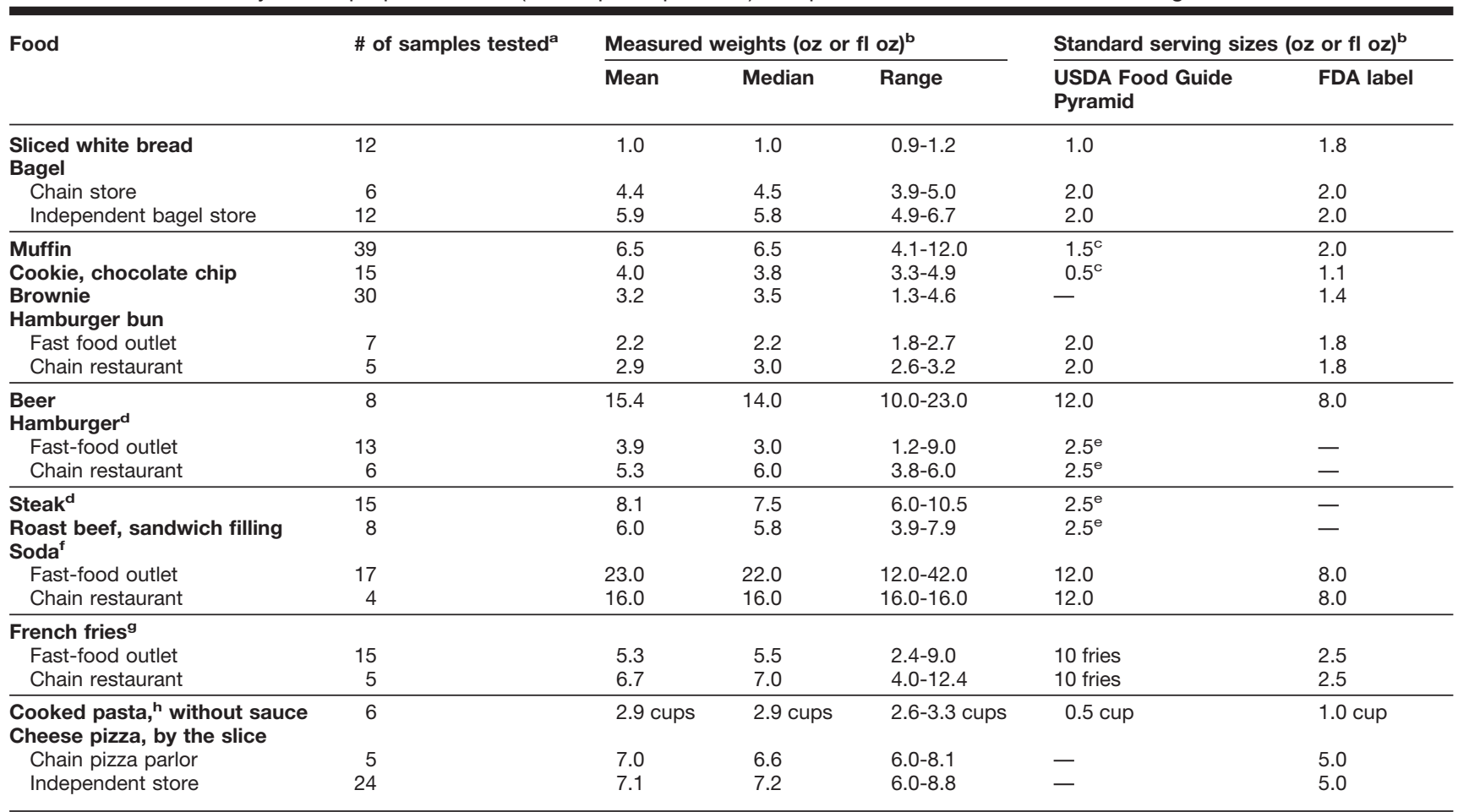

a Sample size varies for items depending on the availability of manufacturers' information on weight and nutrient content. We weighed fewer samples of items labeled with this information (24).

bSizes are stated in ounces (oz) for solid foods (eg, bread, muffins, french fries) or fluid ounces (fl oz) for beverages, unless otherwise indicated.

"Weight of a "medium" serving, derived from USDA definitions. One grain serving=1 oz. One medium muffin=1.5 servings. Two "medium" cookies=one grain serving.

${ }^{\mathrm{d}}$ Cooked weight.

eMean weight of 2 to $3 \mathrm{oz}$, cooked.

fFluid ounce of cup size. Fluid ounce of poured soda will vary by amount of ice added. Chain restaurants offer free refills.

gSizes are stated in ounces, except for USDA Food Guide Pyramid (reference 9) servings of french fries; these are given in by number of fries, not ounces. ${ }^{\mathrm{h}}$ Cooked volume of pasta without sauce, measured in cups.

USDA=US Department of Agriculture.

${ }^{\mathrm{j} F D A}=\mathrm{US}$ Food and Drug Administration

demonstrated that this method would be effective (23). We sampled foods from at least four of each type of venue (eg, four fast-food chains), totaling 32 establishments. Details about the weighing method and its validation are described elsewhere (24). We compared current marketplace portion sizes to USDA and FDA standard servings. We obtained information about past portion sizes directly from manufacturers or indirectly by examining trade publications, professional journals, marketing and advertising publications, menu collections, cookbook recipes, fast-food guides, and older editions of food composition tables.

\section{RESULTS}

Table 1 compares the portion sizes of ready-to-eat prepared foods to federal standard serving sizes. These data indicate that with the exception of sliced white bread, the sizes of marketplace portions exceed federal standards, often by at least a factor of 2 (bagels, sodas) and sometimes by as much as 8 (cookies). Table 2 compares the sizes of selected food products when first introduced with the sizes now available. Manufacturers generally introduced foods in only one size; this size was smaller than or equal to currently available portion sizes (25-27). For example, the original Hershey bar was $0.6 \mathrm{oz}$, but current bars range from 1.6 to 8.0 oz. Fast-food chains offer larger sizes of hamburger, sodas, and french fries; current sizes are often 2 to 5 times larger than the original size. We found additional evidence supporting a trend toward larger portion sizes. Larger sodas are reflected in new names such as "Supersize" or "Double Gulp." Fastfood companies actively promote larger portions with signs, staff pins, and placemats. Reviews refer to large restaurant portions ("Godzilla-sized burgers") (28). Chain restaurants promote larger items on menus ("hefty helpings"). Foodservice establishments use larger dinner plates, larger pans to bake muffins and pizzas, and larger containers for sodas and fries (24). Identical recipes in old and new editions of classic cookbooks such as The Joy of Cooking (29-31) or those for tollhouse cookies $(32,33)$ yield fewer servings today than in the past. Overall, the data suggest an increase in 
Table 2

Marketplace portion sizes of selected foods and beverages when first introduced compared with marketplace portions in $2002^{\mathrm{a}}$

\begin{tabular}{|c|c|c|c|}
\hline \multicolumn{4}{|l|}{ Beer } \\
\hline Bottle, Budweiser & 1976 & 7.0 & $7.0,12.0,22.0,40.0$ \\
\hline \multicolumn{4}{|l|}{ Chocolate bar, milk chocolate } \\
\hline Hershey's & 1908 & 0.6 & $1.6,2.6,4.0,7.0,8.0$ \\
\hline Nestlé Crunch & 1938 & 1.6 & $1.6,2.8,5.0$ \\
\hline McDonald's & 1955 & 2.4 (Fries) & 2.4 (Small), 5.3 (Medium), 6.3 (Large), 7.1 (Supersize) \\
\hline \multicolumn{4}{|l|}{ Hamburger, beef only ${ }^{b}$} \\
\hline McDonald's & 1955 & 1.6 & $1.6,3.2,4.0,8.0$ \\
\hline Howard Johnson's & 1970s & 3.5 & $5.0,8.0$ \\
\hline \multicolumn{4}{|l|}{ Hamburger sandwich ${ }^{c}$} \\
\hline Burger King & 1954 & 3.9 & $\begin{array}{l}4.4 \text { (Hamburger), } 6.0 \text { (Whopper Jr.), } 6.1 \text { (Double hamburger), } \\
9.9 \text { (Whopper), } 12.6 \text { (Double whopper) }\end{array}$ \\
\hline McDonald's & 1955 & 7.0 & $\begin{array}{l}12.0 \text { (Child), } 16.0 \text { (Small), } 21.0 \text { (Medium), } 32.0 \text { (Large), } \\
42.0 \text { (Supersize) }\end{array}$ \\
\hline 7-Eleven stores & 1973 & $\begin{array}{l}12.0 \\
20.0\end{array}$ & $\begin{array}{l}16.0 \text { (Gulp), } 32.0 \text { (Big Gulp), } 44.0 \text { (Super Big Gulp), } \\
64.0 \text { (Double Gulp) }\end{array}$ \\
\hline $\begin{array}{l}\text { Soda, commercially packaged, } \\
\text { Coca Cola, bottle and can }\end{array}$ & 1916 & 6.5 & $8.0,12.0,20.0,34.0$ \\
\hline \multicolumn{4}{|c|}{$\begin{array}{l}\text { anformation obtained from manufacturers. Sizes are stated in ounces (oz) for solid foods such as chocolate bars, french fries, hamburger beef, and sandwiches; } \\
\text { and fluid ounces (fl oz) for beverages such as beer and soda. Manufacturers are the following: Anheuser-Busch, Inc. (St Louis, MO); Burger King Corporation } \\
\text { (Miami, FL); The Coca-Cola Company (Atlanta, GA); Franchise Associates (South Weymouth, MA); Hershey Foods Corporation (Hershey, PA); McDonald's } \\
\text { Corporation (Oakbrook, IL); Nestle USA (Solon, OH); and 7-Eleven, Inc. (Dallas, TX). } \\
\text { bPrecooked beef. } \\
\text { 'Includes cooked beef, bun, vegetable, and condiment. Does not include cheese. }\end{array}$} \\
\hline
\end{tabular}

the sizes of most foods and beverages prepared for immediate consumption.

\section{DISCUSSION}

Our observations have implications for nutrition counseling about healthful eating. Because marketplace portions are consistently larger than USDA standard servings, nutritionists need to explain the difference to clients. The Pyramid recommendation to consume 6 to 11 grain servings/day refers to standard serving sizes. Whereas a standard bagel is 2 oz and 2 grain servings, one marketplace bagel is nearly 6 oz, and, therefore, 6 grain servings, which is sufficient for people consuming 1,600 kcal/day. Similarly, one muffin or one pasta entrée in a restaurant can easily comprise 6 grain servings. This discrepancy explains why many Americans view 6 to 11 grain servings as too much to eat (34). Similarly, a USDA standard meat serving is 2 to 3 $\mathrm{oz}$, and the recommendation is two to three servings for a daily total of 5 to 7 oz, but steak at family-type restaurants typically exceeds 8 oz (3 to 4 standard servings), and steakhouse steaks weigh as much as 24 oz (8 to 12 servings) (35). Because portion distortion is so prevalent among Americans (36), the USDA lists the number of standard servings obtained from eating marketplace portions of several foods (37).

Marketplace portions also exceed standard serving sizes on food labels. Labels list kcal/serving, but individually packaged muffins, candy bars, and single bottles of soda sometimes contain 2.5 or more standard label servings. Adding to this confusion is the FDA rule that a food weighing less than twice the standard serving amount may be labeled "one serving per container." Because a standard soda serving is $8 \mathrm{oz}$, both $8-\mathrm{oz}$ and 12-oz sodas are labeled as one serving, but a $20-0 z$ soda must be labeled as 2.5 servings. Also confusing are the differences between USDA and FDA standard servings. For example, the standard FDA serving of cooked pasta or rice is one cup, but the USDA standard is half as much. These distinctions require clarification, especially as they apply to weight management.

Also needing emphasis is the basic fact that large portions contain more calories than small portions. A McDonald's small french fries (2.4 oz) contains 210 kcal, whereas the "Supersize" (7.1 oz) provides $610 \mathrm{kcal}$; a small Coca-Cola (16 fl oz), more than twice the volume of the original, contains 150 kcal, whereas the "Supersize" (42 oz) contains $410 \mathrm{kcal}$ (38). Together, the larger portions of these two foods provide $1,020 \mathrm{kcal}$, which is half the daily energy required by large segments of the US population (39). A Burger King Double Whopper alone provides nearly $1,000 \mathrm{kcal}$. Giant size chocolate bars are more than ten times larger than the size of bars when first introduced and contain ten times as much energy (26).

The trend toward larger marketplace portions has occurred in parallel with rising rates of obesity. Much evidence supports a causal connection. The availability of energy in the US food 
supply also has increased in parallel (40), as has energy intake reported in dietary surveys (41). For complicated reasons of farm policy, the low cost of basic food commodities means that larger portions do not cost much more $(42,43)$. Larger portions encourage people to eat more (44-47) and stimulate sales of products to adults $(48,49)$ and children (50).

\section{APPLICATIONS}

- Many Americans believe that the kind of food they eat is more important than its quantity (51). On quantitative grounds alone, clients need to be advised about the relationship of marketplace portions to standard servings. Nutritionists counseling clients-and the public-about healthy eating and weight loss strategies should make every effort to emphasize the relationship between portion sizes, energy intake, and weight management. Even though it may seem intuitively obvious, we cannot overemphasize the point that larger portions contain more calories.

\section{References}

1. Young LR, Nestle M. The contribution of expanding portion sizes to the U.S. obesity epidemic. Am J Public Health. 2002;92:246-249.

2. National Institutes of Health, National Heart, Lung, and Blood Institute. Clinical Guidelines on the Identification, Evaluation, and Treatment of Overweight and Obesity in Adults. Bethesda, Md: National Institutes of Health, National Heart, Lung, and Blood Institute, 1998. Publication 984083 .

3. Flegal KM, Carroll MD, Ogden CL, Johnson $\mathrm{CL}$. Prevalence and trends in obesity among US adults, 1999-2000. JAMA. 2002;288:1723-1727. 4. Ogden CL, Flegal KM, Carroll MD, Johnson CL. Prevalence and trends in overweight among US children and adolescents, 1999-2000. JAMA. 2002;288:1728-1732.

5. US Department of Health and Human Services. The Surgeon General's Call to Action to Prevent and Decrease Overweight and Obesity. Rockville, MD: US Department of Health and Human Services, Public Health Service, Office of the Surgeon General; 2001.

6. Young LR, Nestle M. Variation in perceptions of a "medium" food portion: Implications for dietary guidance. J Am Diet Assoc. 1998;98:458-459.

7. Hogbin MB, Hess MA. Public confusion over food portions and servings. J Am Diet Assoc. 1999;99:1209-1211.

8. US Department of Health and Human Services. The Surgeon General's Call to Action to Prevent and Decrease Overweight and Obesity. Overweight and Obesity Fact Sheet: Surgeon General's Healthy Weight Advice for Consumers. Available at: http://www.surgeongeneral.gov/topics. obesity/calltoaction/fact_advice.htm. Accessed $1 / 17 / 2002$.

9. US Department of Agriculture. The Food Guide Pyramid. Revised ed. Washington, DC: US Dept of
Agriculture, 1996. Home and Garden Bulletin No. 252.

10. Cronin FJ, Shaw AM, Krebs-Smith SM, Marsland PM, Light L. Developing a food guidance system to implement the dietary guidelines. $J$ Nutr Educ. 1987;19:281-302.

11. US Department of Agriculture. USDA's Food Guide: Background and Development. Hyattsville, Md: US Dept of Agriculture, Human Nutrition Information Service, 1992. Administrative Report No. 389

12. Pao EM, Fleming KH, Guenther PM, Mickle SJ. Foods Commonly Eaten by Individuals: Amounts per Day and per Eating Occasion. Home Econ Res Rep 44. Hyattsville, Md: USDA, 1982.

13. US Department of Agriculture, US Department of Health and Human Services. Nutrition and Your Health: Dietary Guidelines for Americans. 5th ed. Washington, DC: US Dept of Agriculture, 2000. Home and Garden Bulletin No. 232

14. Heimbach JT, Levy AS, Schucker RE. Declared serving sizes of packaged foods, 1977-86. Food Technol. 1990;44:82-90.

15. Food and Drug Administration. Food labeling: serving sizes. Federal Register. 1993;58:22292291.

16. Young LR, Nestle M. Portion sizes in dietary assessment: issues and policy implications. Nutr Rev. 1995;53:149-158.

17. Clauson A. Shares of food spending for eating reaches 47 percent. FoodReview. 1999;22:20-22. 18. Klara R. Annual franchise report: hot prospects. Restaurant Business. 1996;95:87-121.

19. Restaurant Business. Top 50 growth chains. Restaurant Business. 1996;95:51-122.

20. Lowe KD, Nicolas E. The top 400 restaurant concepts. Restaurants and Institutions. 1997;107: 17.

21. Block G, Dresser CM, Hartman AM, Carrol MD. Nutrient sources in the American diet: Quantitative data from the NHANES II survey. Am J Epidemiol. 1985;122:27-40.

22. Subar AF, Krebs-Smith SM, Cook A, Kahle LL. Dietary sources of nutrients among US adults, 1989 to 1991. J Am Diet Assoc. 1998;98:537-547. 23. Young LR, Nestle M. Food labels consistently underestimate the actual weights of single-serving baked products. J Am Diet Assoc. 1995:95:11501151.

24. Young LR. Portion Sizes in the American Food Supply: Issues and Implications [Dissertation]. New York, NY: New York University; 2000.

25. Anheuser-Busch, Inc. The History of Anheuser-Busch Companies: A Fact Sheet. St. Louis: Anheuser Busch, Inc.; 1995.

26. Hershey Foods Corporation. Bar weight history. Hershey, Pa: Hershey Foods Corporation; 1991.

27. Coca-Cola Company. Facts, Figures, and Features. Atlanta, GA: Coca-Cola Company, 1996.

28. Zagat Survey. Zagat Survey 2000: New York City Restaurants. New York: Zagat Survey, 1999.

29. Rombauer IS, Becker MR. Joy of Cooking. New York: Penguin Books USA; 1964.

30. Rombauer IS, Becker MR. Joy of Cooking. New York: Penguin Putnam; 1975.

31. Rombauer IS, Becker MR, Becker E. Joy of Cooking. New York: Scribner; 1997.

32. Wakefield R. Ruth Wakefield's Tollhouse Tried and True Recipes. New York: M. Barrows; 1949.

33. The Nestle Foods Corporation. Nestle Tollhouse chocolate chip cookies [Advertisement]. Ladies Home Journal. 1987;Dec:166,167.

34. Hogbin M, Shaw A, Anand RS. Nutrition Insights: Food Portions and Servings. How Do They Differ? Washington, DC: US Dept of Agriculture; 1999.

35. Bernstein C. At steak ... Restaurants and Institutions. 1997;107:72-74.

36. American Dietetic Association. Nutrition and you: Trends 2002. American Dietetic Survey shows Americans can use some help in sizing up their meals. Available at: http://www.eatright.org. Accessed 8/26/2002.

37. US Department of Agriculture. How Much Are You Eating? Washington, DC: Center for Nutrition Policy and Promotion, 2002. Home and Garden Bulletin No. 267-1.

38. McDonald's Corporation. McDonald's Nutrition Facts. Oakbrook, III: McDonald's Corporation; 1999.

39. National Research Council. Recommended Dietary Allowances. 10th ed. Washington, DC: National Research Council, National Academy Press; 1989.

40. Putnam JJ, Allshouse JE. Food Consumption, Prices, and Expenditures. Washington, DC: US Dept of Agriculture, Economic Research Service, 1999. Statistical Bulletin No. 965.

41. US Department of Agriculture. Data tables: results from USDA's 1994-1996 continuing survey of food intakes by individuals and 1994-96 diet and health knowledge survey, December 1997. Available at: http://www.barc.usda.gov/bhnrc/ foodsurvey/home.htm. Accessed 2/25/1999.

42. Nestle M. Food Politics: How the Food Industry Influences Nutrition and Health. Berkeley: University of California Press; 2002

43. National Alliance for Nutrition and Activity (NANA). From Wallet to Waistline: The Hidden Costs of Super Sizing. Washington, DC: NANA; June 2002.

44. Rolls BJ, Morris EL, Roe LS. Portion size of food affects energy intake in normal-weight and overweight men and women. Am J Clin Nutr. 2002;76:1207-1213.

45. Rolls BJ, Engell D, Birch LL. Serving portion size influences 5-year-old but not 3-year-old children's food intakes. J Am Diet Assoc. 2000;100: 232-234.

46. Edelman B, Engell D, Bronstein P, Hirsch E. Environmental effects on intake of overweight and normal-weight men. Appetite. 1986;7:71-83.

47. Wansink B. Can package size accelerate usage volume? J Marketing. 1996;60:1-13.

48. Hollingsworth P. Self-indulgence trends. Food Technol. 1999:53:64-65.

49. Information Resources Inc. At the checkout: big sales for big products. Wall Street Journal. Oct 12, 1993:B1

50. Nelson E. Finger food: Marketers push individual portions and families bite. Wall Street Journal. July 23, 2002:A1,6.

51. American Institute of Cancer Research. New survey shows Americans ignore importance of portion size in managing weight. Available at: http://www.aicr.org. Accessed 10/27/2000.

This study was part of Dr. Young's dissertation research at New York University and was supported in part by a scholarship from the Department of Nutrition and Food Studies and a Dean's Grant for Student Research from the Steinhardt School of Education at New York University.

The authors thank professors Jeffrey Backstrand, Sally Guttmacher, and Sharon Weinberg for advice while conducting the study and Adrienne Forman for helpful suggestions. 